International Journalof Sustainable Energy

\title{
Multiobjective assessment of distributed energy storage location in electricity networks
}

José António Ribeiro Gonçalves, Luís Pires Neves \& António Gomes Martins

To cite this article: José António Ribeiro Gonçalves, Luís Pires Neves \& António Gomes Martins (2017) Multiobjective assessment of distributed energy storage location in electricity networks, International Journal of Sustainable Energy, 36:6, 577-591, DOI: 10.1080/14786451.2015.1066787

To link to this article: https://doi.org/10.1080/14786451.2015.1066787

曲 Published online: 28 Jul 2015.

Submit your article to this journal $\pi$

Џll Article views: 176

View Crossmark data \lceil

Citing articles: 1 View citing articles 


\title{
Multiobjective assessment of distributed energy storage location in electricity networks
}

\author{
José António Ribeiro Gonçalves (iD) a,b*, Luís Pires Neves (iD) ${ }^{\mathrm{a}, \mathrm{b}, \mathrm{c}}$ and \\ António Gomes Martins (1Da,b \\ ${ }^{a}$ Energy for Sustainability Initiative, University of Coimbra, Coimbra, Portugal, ${ }^{b}$ INESCC - Institute for \\ Systems Engineering and Computers at Coimbra, Coimbra, Portugal, ${ }^{c}$ Polytechnic Institute of Leiria, \\ Leiria, Portugal
}

(Received 1 April 2015; accepted 21 June 2015)

\begin{abstract}
This paper presents a methodology to provide information to a decision maker on the associated impacts, both of economic and technical nature, of possible management schemes of storage units for choosing the best location of distributed storage devices, with a multiobjective optimisation approach based on genetic algorithms. The methodology was applied to a case study, a known distribution network model in which the installation of distributed storage units was tested, using lithium-ion batteries. The obtained results show a significant influence of the charging/discharging profile of batteries on the choice of their best location, as well as the relevance that these choices may have for the different network management objectives, for example, for reducing network energy losses or minimising voltage deviations. Results also show a difficult cost-effectiveness of an energy-only service, with the tested systems, both due to capital cost and due to the efficiency of conversion.
\end{abstract}

Keywords: energy storage; power distribution networks; energy profiles; load levelling energy service; improved genetic algorithms

\section{Introduction}

Electricity distribution networks presently face many challenges due to the need to integrate distributed generation, continuous load growth, increasing power quality requirements of electronic loads and higher regional power transfers in a largely interconnected network (Ribeiro et al. 2001).

These new challenges can lead to a more complex and less secure power system operation, especially because power plants may not be able to follow new demands as a result of economic, environmental, technical and governmental regulation constraints (Ribeiro et al. 2001; Vitorino, Jorge, and Neves 2013a).

In the context of a microgrid environment, distributed electric energy storage systems (DEESS) are presented as an option to enable the optimisation of resources, by providing the capability of effectively balancing supply and demand (EPRI 2010). However, a methodology is needed to provide the decision maker (DM) with information on the associated impacts, both

*Corresponding author. Email: jagoncalves@gmail.com 
economic and technical, of possible DEESS management schemes, for choosing the best location of storage devices.

This paper presents one such methodology, based on genetic algorithms (GA), taking into consideration the desired operating profile of the storage units to provide a specific energy service, using only publicly available data from the energy sector.

\section{Electrical energy storage systems}

New challenges arise regarding the balance between supply and demand due to the increasing penetration of distributed renewable generation on the network. Energy storage systems (ESS) are proposed by many authors as an opportunity to solve many problems of network capacity and reliability (Ribeiro et al. 2001; Divya and Østergaard 2009), despite being pointed out as unprofitable (Dufo-López and Bernal-Agustín 2015).

Previous research assessing the impact of ESS on the power system operation and economics has been mainly focused on economic/optimal sizing. ESS has been modelled from the point of view of cost or with a focus on the assessment of operational benefits, considering the ESS response to power system disturbances at appropriate time scales (Divya and Østergaard 2009).

Most studies performing economic analysis of ESS considered vertically integrated utilities, not incorporating market models to assess the benefits of ESS for the present day deregulated market. On the other side, the majority of studies concerning the impact on power systems usually do not refer to any particular battery type, or to any limitation of the performance of ESS (Divya and Østergaard 2009). Nevertheless, some authors have included technology characteristics in their models (Dufo-López and Bernal-Agustín 2015; Fossati et al. 2015).

Focusing on the economic dimension, some authors presented methodologies for evaluating the associated costs and benefits of energy storage by analysing single specific services (Kempton and Tomić 2005; Schoenung 2011). However, none of these studies consider the relation of an ESS management scheme (MSch) with its associated impacts on the network performance.

Regarding operational benefits, the advantages of storage led to the idealisation of the vehicleto-grid concept, a long-held idea of an option to provide specific energy services to the grid based on the batteries of connected electric vehicles (EV). Different methodologies were then developed to analyse their contribution to the grid (Balcells and García 2010; Kristoffersen, Capion, and Meibom 2011; Lopes, Soares, and Almeida 2011; Lassila et al. 2012). However, the uncertainty associated with the location of EV led these authors to be primarily concerned with this constraint (Battistelli, Baringo, and Conejo 2012). To assess the possible contribution in terms of energy exchange to the grid, Lassila et al. (2012) tested the effect of different charging/discharging (C/D) schemes to provide specific energy services.

The majority of studies present in literature are only focused on one type of evaluation, technical or economic, and usually do not provide more than one option for a DM to choose from. However, effective decisions over the subject will need to simultaneously consider both kinds of objectives, and even different objectives of each kind, and should imply a multiobjective optimisation procedure.

Recently proposed multiobjective methodologies use different strategies to obtain the most suited daily profile of the state of charge of batteries, whose locations depend on the average loads of network buses, minimising the energy losses in the grid, the total electricity generation cost and the greenhouse gas emissions (Ippolito et al. 2014).

Other ESS advantages are the ability to postpone grid reinforcements, avoid short interruptions and voltage quality problems, shave power peaks and smooth load curves (Lassila et al. 2012). However, the economic attractiveness of storage is not guaranteed, especially due to the high 
capital cost when compared to alternative technologies. Therefore, the proposal of a feed-in tariff scheme is justified to increase the interest of investors (Dufo-López and Bernal-Agustín 2015).

The main barrier to ESS deployment seems to be related to the existence of a large number of conventional generators (Divya and Østergaard 2009) that can be dynamically adjusted to match the load demand (LD), the interconnection of areas and the reluctance of network operators to integrate resources that they do not manage (Sovacool and Hirsh 2009). To overcome these barriers it is crucial to improve the application and benefits of this type of systems, namely by developing operational tools to select the quantity and location of these resources, optimise the operational cost and assess the benefits of storage during the planning phase (Divya and Østergaard 2009; EPRI 2010).

The novelty of the proposed methodology is to combine the determination of the best location for the storage units with the definition of the best schedule of operation when simultaneously minimising investment costs, energy losses and voltage deviations (VD), as well as maximising the economic benefit resulting from the energy exchange with the grid.

\section{Optimisation tool}

GA belong to the larger class of evolutionary algorithms, comprising a search technique that provides exact or approximate solutions, based on the evolution of organisms. GA have been widely used for combinatorial optimisation problems in power systems, such as economic dispatch, rearrangement of power networks, optimal placement of capacitors or inductors and optimal power flow analysis (Miranda, Srinivasan, and Proença 1998; Chen et al. 2013).

For the proposed methodology, the use of a multiobjective approach is justified by the presence of different conflicting objectives which prevent the achievement of an optimal solution. The identification of the solution that better suits the DM perspective needs an explicit or implicit definition of tradeoffs between objectives. This definition can be made ex-ante, or after the optimisation process. In the latter case, a set of non-dominated solutions is produced, needing further analysis in order to achieve the desired result, but it avoids a previous non-trivial definition of the structure of preferences of the DM.

The Non-dominated Sorting Genetic Algorithm II (NSGA-II) is an effective tool to solve combinatorial multiobjective problems, namely in power distribution operation and planning (Sahoo and Prasad 2006). In the described work, the NSGA- II (Deb et al. 2002) was adapted as proposed in Vitorino, Jorge, and Neves (2013b). Namely, the fixed genetic operators of conventional NSGA-II were replaced with a dynamic adaptation of crossover $(p c)$ and mutation $(p m)$ probabilities, according to the genetic diversity of the population. In the work described in this paper, the dynamic probabilities' maximum and minimum values were limited as shown in Table 1.

\subsection{Optimisation objectives}

Considering a $24 \mathrm{~h}$ time horizon, the assessment of the best locations for DEESS consists in the identification of the buses where installed storage units would minimise network energy losses

Table 1. Dynamic data for the optimisation tool.

\begin{tabular}{lcccccc}
\hline Designation & Pmmin & Pmmax & Pcmin & Pcmax & Bmin & Bmax \\
\hline Value & 3 & 25 & 50 & 100 & 0 & 100 \\
\hline
\end{tabular}


(NEL), network voltage quadratic mean deviation (NVqmd) and network storage annualised cost (NSAC), when maximising the benefit associated with the daily purchase and sale of energy in different time periods, hereinafter designated as network energy rate benefit (NERB).

The NEL objective function, described in Equation (1), is the sum of the network power losses (PL) in all the $n$ branches of the medium voltage (MV) distribution network. The elementary time interval is a quarter-hour $\left(t_{j}=0.25 \mathrm{~h}\right)$ so the data set has 96 values $(m=96)$.

$$
\min . \mathrm{NEL}=\sum_{i=1}^{n} \sum_{j=1}^{m} \frac{\mathrm{PL}_{i j}}{t_{j}} .
$$

The NVqmd objective function, described in Equation (2), is the maximum daily network voltage quadratic mean deviation (NVqmd) for all individual VD in the $N$ network buses.

$$
\min . \mathrm{NVqmd}=\operatorname{Max} \sqrt{\frac{\sum_{k=1}^{N} \mathrm{VD}_{k}^{2}}{N}} .
$$

The NSAC objective function, described in Equation (3), considers the cost for installing $x$ units of DEESS with an individual capital cost $\left(C_{a c}\right)$.

$$
\min . \mathrm{NSAC}=x \times C_{a c} .
$$

$C_{a c}$ is calculated considering the global capital costs $\left(c_{c}\right)$ and the capital recovery factor (CRF) as presented in equation (4), where $d$ is the dimensionless discount rate and $y$ the expected life of the equipment, measured in years;

$$
C_{a c}=c_{c} \mathrm{CRF}=c_{c} \frac{d(1+d)^{y}}{(1+d)^{y}-1} .
$$

The NERB objective function, described in Equation (5), considers the energy tariff $(C)$ and the required energy $(E)$ to charge (ch) and discharge (dch) in one day.

$$
\max \cdot \mathrm{NERB}=\sum_{j=1}^{m}\left(E_{\mathrm{dch}} \times C_{\mathrm{dch}}-E_{\mathrm{ch}} \times C_{\mathrm{ch}}\right)_{j} .
$$

\section{Model explanation}

The proposed methodology consists on finding the Pareto front for each scenario, feeding the optimisation tool with the network, technology characterisation and service definition data, which produces the best possible DEESS locations, as presented in Figure 1.

The service definition block is where the desired goal to be assessed is specified through management schemes. In the present paper the authors tested three plausible goals for ESS which are presented in Section 4.3.

The technology characterisation block defines the technical characteristics of the considered ESS (battery plus power converter (PC)), since solutions depend on the considered technology and its working limits. This block provides information about the working periods for the MSch (C/D profile) in the DE ESS working profile block and the capacity limits used in the optimisation process, namely in the power flow analysis performed inside the genetic search block.

The network characterisation block defines the daily demand diagram of the distribution substation and the active and passive elements of the electricity grid. In this step it is necessary to 


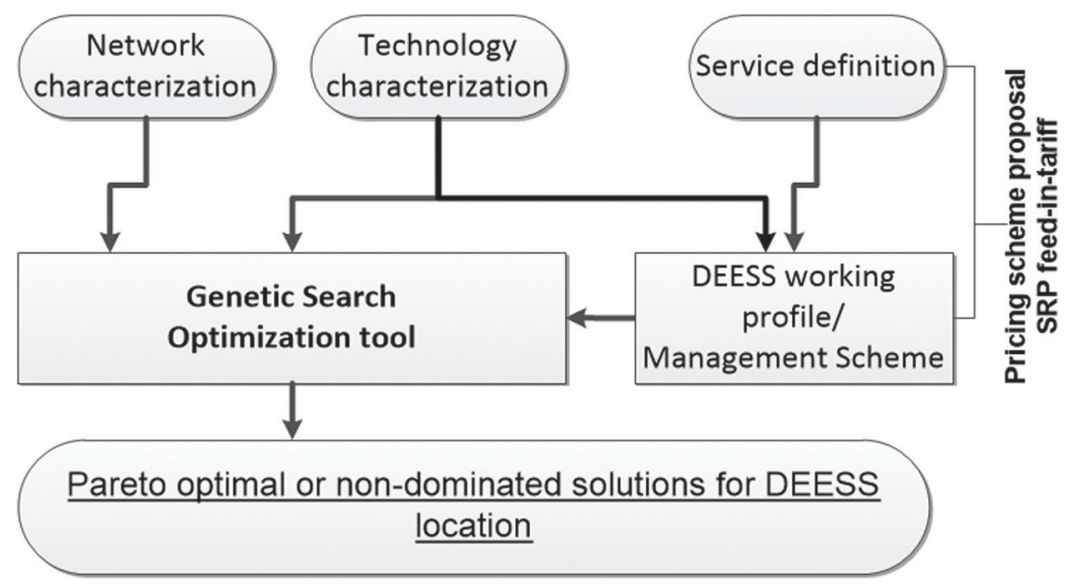

Figure 1. Proposed methodology for DEESS assessment using an optimisation algorithm.

characterise the entire network, describing cables, buses and interconnections. The information is compiled in data matrixes loaded in the Matlab software, which are used by the Matpower toolbox for power flow analysis, thus allowing the study of any type of grid.

The DEESS working profile block, presented in Figure 1, represents an intermediate stage for the MSch definition of the considered ESS. Therefore, it combines the management goals of the DM, registered in the Service definition step, and the technical limits of the considered ESS.

All the possible solutions are presented in the Pareto optimal front as a result of the optimisation tool process. The final preferred solution must be chosen by the DM considering its own perception and assumed tradeoffs between objectives.

\subsection{Model constraints}

The operation of ESS is constrained by the individual capacities of each storage unit which was specified considering the required voltage for the power inverter, a power limit which considers the minimum values of the bus capacities in the case study, and the physical limit of each individual storage solution for a maximum volume of $1 \mathrm{~m}^{3}$, specified in order to be easily installed within a typical distribution transformer (DT) station (EDP Distribuiçao 2004). For the specific case study, a power limit of $4.35 \mathrm{~kW}$ was chosen, resulting in the exclusion of five buses with lower capacities.

\subsection{Proposal of a pricing scheme for the energy storage service}

In the course of methodology development it became evident that buying and selling energy in different periods using the wholesale market rates, for battery charging and discharging operations, did not return a significant income.

The energy storage business model is less simple to assess than the renewable electricity generation business model. In fact, in this latter case, primary energy is costless, whereas in a storage business promoted by an independent operator (either the distribution system operator (DSO) or a private investor) the energy to be delivered has to be purchased.

As in any business, there must be a way of integrating into the selling price the value added by the intervention of the economic agent at stake. The authors considered, for this purpose, a thoroughly used approach in the renewable electricity generation business, the feed-in tariffs. In 


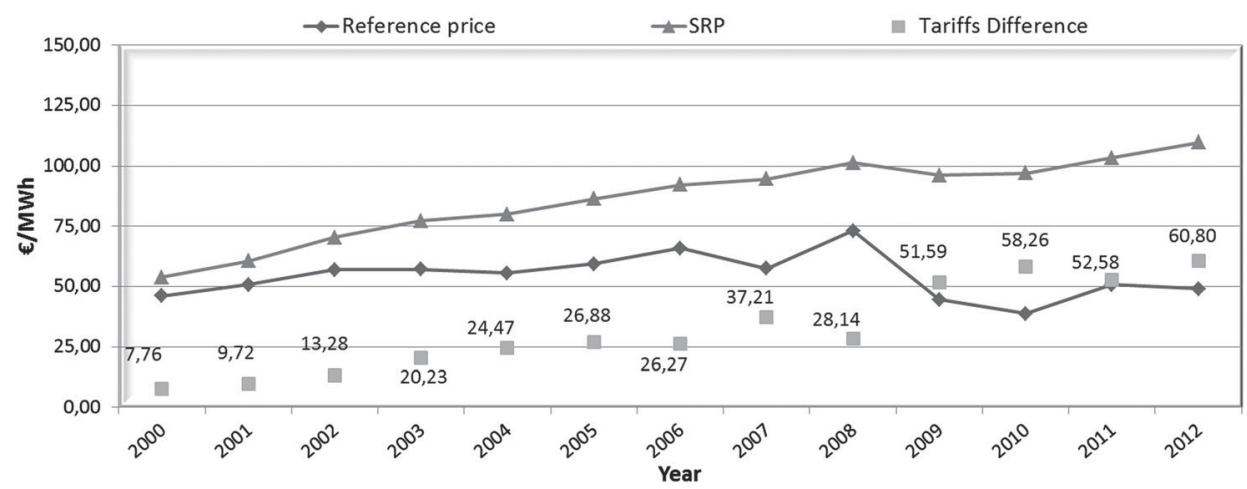

Figure 2. Comparison between prices paid to SRP and the reference price for the regulated market, using Portugal as an example (ERSE 2013).

the context of the case study, revenues of ESS are considered in an equal footing with those of a special regime producer (SRP), Portuguese designation for non-conventional energy producers.

However, to enable private investment in this process, legislation must be adapted to include storage as a target to support.

SRP prices for the period between 2000 and 2012 in Portugal are presented in Figure 2. In the paper an average SRP surplus (on top of the wholesale market price) feed-in tariff of $28.14 € / \mathrm{MWh}$ was used, as it corresponds to the same year of the case-study data on energy consumption.

\subsection{ESS service definition}

The impact of a particular ESS management scheme on the power grid may be assessed through the effect it causes on load diagrams. The present paper considers energy and power services, aiming at levelling out the disparities between occurrences of abundant renewable production and concentrations of LD.

The current case study considers three possible MSch goals that are more frequently mentioned in the literature:

(1) MSch 1 - To maximise profit from daily energy spot market rates;

(2) MSch 2 - To minimise daily energy distribution network losses;

(3) MSch 3 - To maximise profit from wind generation.

These MSch establish three possible C/D profiles to be evaluated in terms of return on investment, network losses, VD and net benefit of energy buying and selling operations in different time periods.

In MSch 1 and 2, charging periods were established to use the periods of lowest rates and minimum network PL, while the discharging periods were defined for the highest rates and maximum PL. The duration of the C/D periods were based on technical limitations presented by the ESS manufacturers, namely a 3-h charge and 1-h discharge, the ON/OFF transition for the battery being assumed to be instantaneous.

For MSch 3, a previous comparative analysis was made between the daily normalised load diagram and the daily normalised diagram of wind energy production, in order to control the amount of renewable energy supplied to the grid.

The assumptions made regarding the definition of the types of services to be provided by the DEESS and its associated working profile are tied to the previously assumed pricing scheme. 


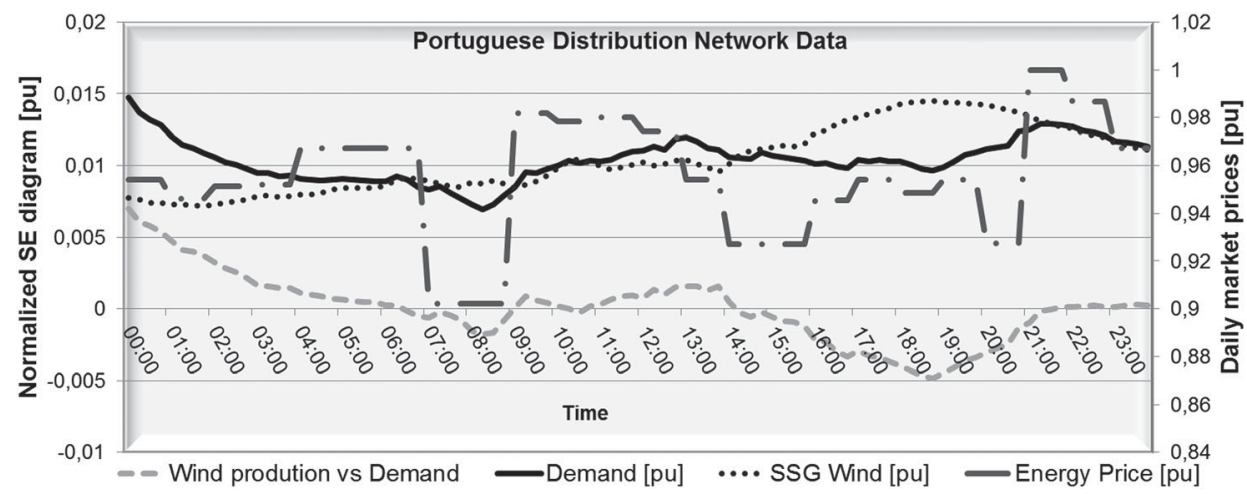

Figure 3. Comparison between normalised distribution grid LD, wind energy production and retail market prices in Portugal of 10 May 2008.

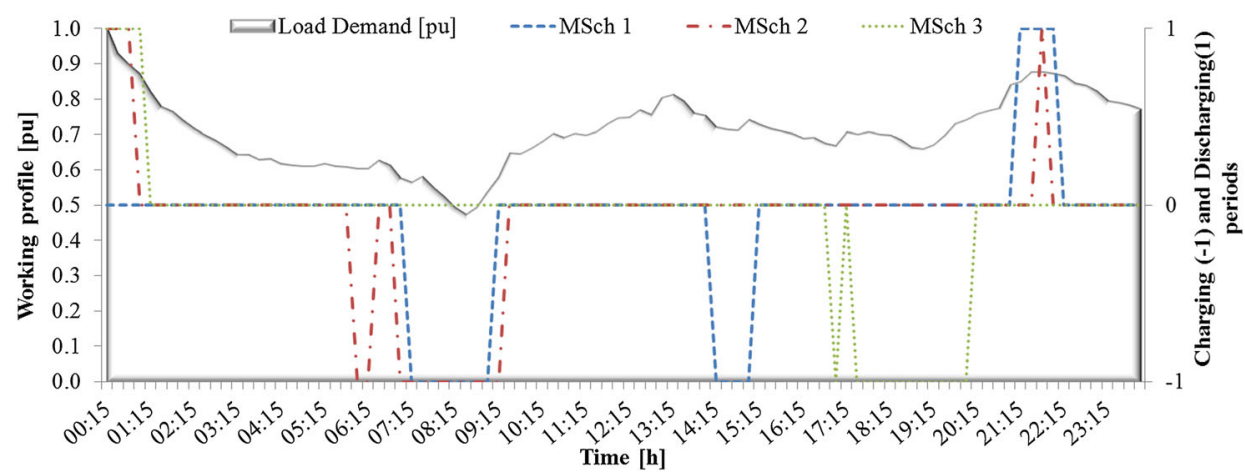

Figure 4. C/D profiles for the three considered schemes.

As Figure 3 clearly shows, there is a lack of correlation between market prices and renewable generation. Since most of the energy sector players react to price stimuli, this lack of correlation may lead to very critical grid management situations depending on the substation geographical location or on the specific day chosen. This phenomenon indicates that it may be advantageous to use a local price scheme, more adapted to the cost of supply near consumption.

The use of energy market rates not correlated to consumption may lead to the use of DEESS strictly for economic purposes, taking the most out of price differences occurring during the day for defining C/D cycles time and duration, irrespective of the actual physical operating conditions of the network. This will cause management inadequacy and overall network operation inefficiency. Moreover, under these conditions, as the technical DEESS benefits will not be exploited, network operators will continue being reluctant to the integration of DEESS into the grid infrastructure (Divya and Østergaard 2009).

The resulting C/D profile for each MSch in the case study is presented in Figure 4, as an example and was converted into a C/D matrix to be used in the optimisation process.

\subsection{Network Characterisation}

The case study made use of the IEEE 69 bus three-phase balanced $12.66 \mathrm{kV}$ RDS as a frequently used test network (Sahoo and Prasad 2006; Vitorino, Jorge, and Neves 2013b). The network includes an 8 MVA substation and 69 nodes, 48 being load-points (DTs) with a total power of 


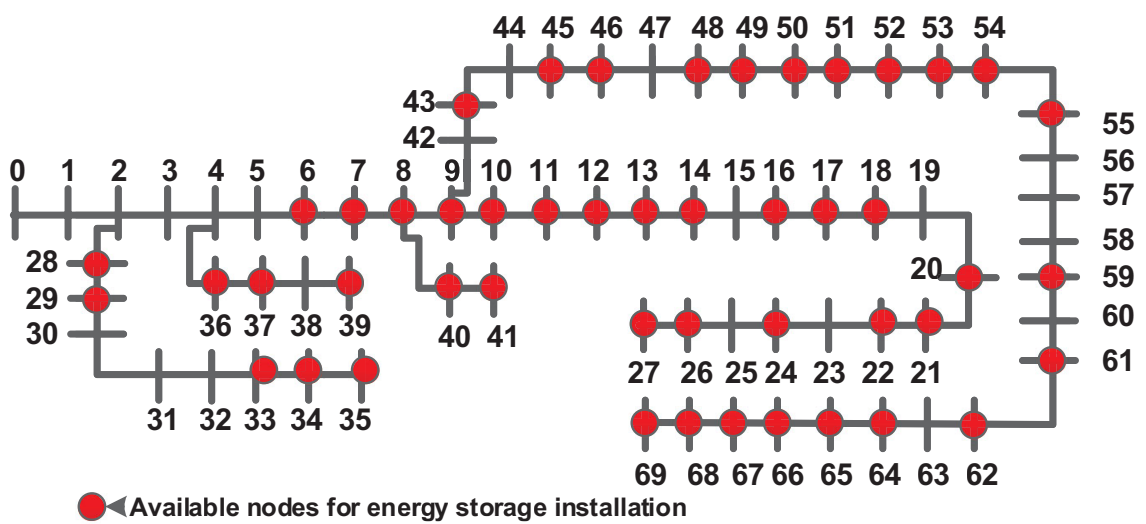

Figure 5. $12.66 \mathrm{kV}$ radial distribution systems (Sahoo and Prasad 2006).

4.66 MVA (peak period) of which 3.8 MW is active power and 2.69 MVAr is reactive power. The network in its radial configuration had all the boundary tie-switches in the open position.

As shown in Figure 5, the proposed RDS included 48 DTs which are considered as possible locations for the installation of the ESS units.

In order to simulate the evolution of the load, the authors used data resulting from a measurement held by the Portuguese DSO on 10 May 2008, at a distribution substation located in the city of Leiria that supplies the parish of Marrazes. The energy retail market prices used in this study were extracted from the derivatives exchange MIBEL database (OMIP 2013) for the same day. A visual representation of this data is presented in Figure 3.

\subsection{ESS characterisation}

The data used in simulations to characterise ESS units were obtained from manufacturers of lithium ion battery technologies. The selected system consists on a lithium-ion phosphate battery (TS-LFP40AHA) and its recommended PC. The battery and PC characteristics are presented in Thunder Sky (2007) and Marra et al. (2012), respectively, and were used to estimate a total consumed energy of $146 \mathrm{Wh} /$ cell. However, the manufacturer recommends a maximum depth of discharge of $80 \%$ of the battery capacity, leading to a final available energy of roughly 117 $\mathrm{Wh} /$ cell. Using the manufacturer's data, the 1CA (Cranking amperes) discharging profile was chosen, corresponding to a discharging current of $38.4 \mathrm{~A}$, with $2.5 \mathrm{~V} /$ cell, or a discharging power of $96 \mathrm{~W} /$ cell (Thunder Sky 2007). The proposed solution requires a volume of $0.1 \mathrm{~m}^{3}$ for the installation of the battery systems (a battery pack of 100 cells) without PC. Such volume can be easily accommodated in most DT facilities (EDP Distribuiçao 2004).

The efficiency of PC has been improving, with several manufacturers claiming values around 90\% (Marra et al. 2012; NEC 2013; Systems 2013). Assuming the combined efficiency is expected to increase, the authors decided to test the methodology using just the battery efficiency of $82.10 \%$ as global efficiency of the system. For the sake of simplicity, the authors assumed only one C/D cycle per day and the pre-defined ESS capacity.

Considering the maximum required discharging capacity and the reference prices for ESS and PC in (Vasconcelos et al. 2012) and (Schoenung 2011), the capital cost was calculated in $6336.00 €$, namely $2534.40 €$ for the PC and $3801.60 €$ for the storage unit. Assuming an interest rate of $8 \%$ and a lifetime of five years, the resulting annualised capital cost was $1586.89 €$. 


\subsection{Results and discussion}

In order to simplify the analysis, results were organised in graphics as presented in Figure 6. The reference values of losses and VD were obtained by analysing the system without energy storage, resulting in an NEL of $5529.08 \mathrm{kWh}$ and an NVqmv of $0.0684 \mathrm{pu}$. The results were obtained using a GA with a population of possible solutions composed by 150 individuals, and a maximum number of 100 generations, assuring convergence.

The reduced impact was due to the limited capacity, resulting in a reduced energy exchange between DEESS and the network, as well as in the efficiency of the system.

Results also show that the impact range of the admissible solutions depends on the considered goals for the MSch. Although the three considered schemes resulted in a positive NEL net benefit, each Pareto front has a different impact range on the optimisation objectives.

As shown in Table 2, storage can have a net positive influence reducing energy losses for identical daily periods, but the results of the current case study are quite small.

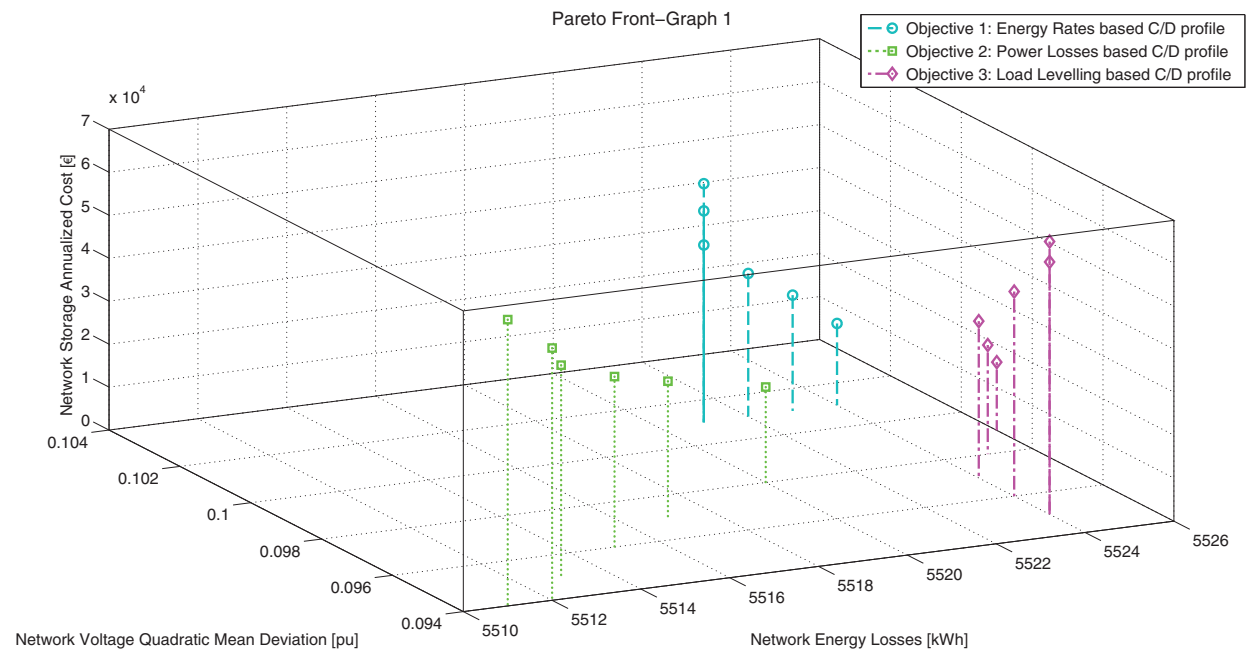

Figure 6. 3D representation results for NEL, NVqmd, NERB.

Table 2. Impact range of the admissible solutions for the three scenarios.

\begin{tabular}{|c|c|c|c|c|c|c|c|c|}
\hline & \multicolumn{2}{|c|}{ NEL } & \multicolumn{2}{|c|}{ NVqmd } & \multicolumn{2}{|c|}{ NSAC } & \multicolumn{2}{|c|}{ NERB } \\
\hline & Min. & Max. & Min. & Max. & Min. & Max. & Min. & Max. \\
\hline MSch 1 & 5521.00 & 5524.00 & 0.1010 & 0.1010 & 19043.00 & 55541.00 & 2.00 & 6.00 \\
\hline Original value & \multicolumn{2}{|c|}{5529} & \multicolumn{2}{|c|}{0.068} & \multicolumn{2}{|c|}{-} & \multicolumn{2}{|c|}{-} \\
\hline Variation (\%) & 99.85 & 99.91 & 147.57 & 147.57 & - & - & - & - \\
\hline Periods & - & - & Charging & Discharging & - & - & - & - \\
\hline Daily variation & - & - & $0.00172 \mathrm{pu}$ & $-0.00455 \mathrm{pu}$ & - & - & - & - \\
\hline MSch 2 & 5511.00 & 5520.00 & 0.0940 & 0.0980 & 22216.00 & 66649.00 & 2.00 & 6.00 \\
\hline Original value & \multicolumn{2}{|c|}{5529} & \multicolumn{2}{|c|}{0.068} & \multicolumn{2}{|c|}{-} & \multicolumn{2}{|c|}{-} \\
\hline Variation & $99.67 \%$ & $99.84 \%$ & $137.34 \%$ & $143.19 \%$ & - & - & - & - \\
\hline Periods & - & - & Charging & Discharging & - & - & - & - \\
\hline Daily variation & - & - & $0.001885 \mathrm{pu}$ & $-0.00519 \mathrm{pu}$ & - & - & - & - \\
\hline MSch 3 & 5524.00 & 5526.00 & 0.0950 & 0.0990 & 15869.00 & 63476.00 & 1.00 & 6.00 \\
\hline Original value & \multicolumn{2}{|c|}{5529} & \multicolumn{2}{|c|}{0.068} & \multicolumn{2}{|c|}{-} & \multicolumn{2}{|c|}{-} \\
\hline Variation (\%) & 99.91 & 99.94 & 138.81 & 144.65 & - & - & - & - \\
\hline Periods & - & - & Charging & Discharging & - & - & - & - \\
\hline Daily variation & - & - & $0.00169 \mathrm{pu}$ & $-0.00442 \mathrm{pu}$ & - & - & - & - \\
\hline
\end{tabular}




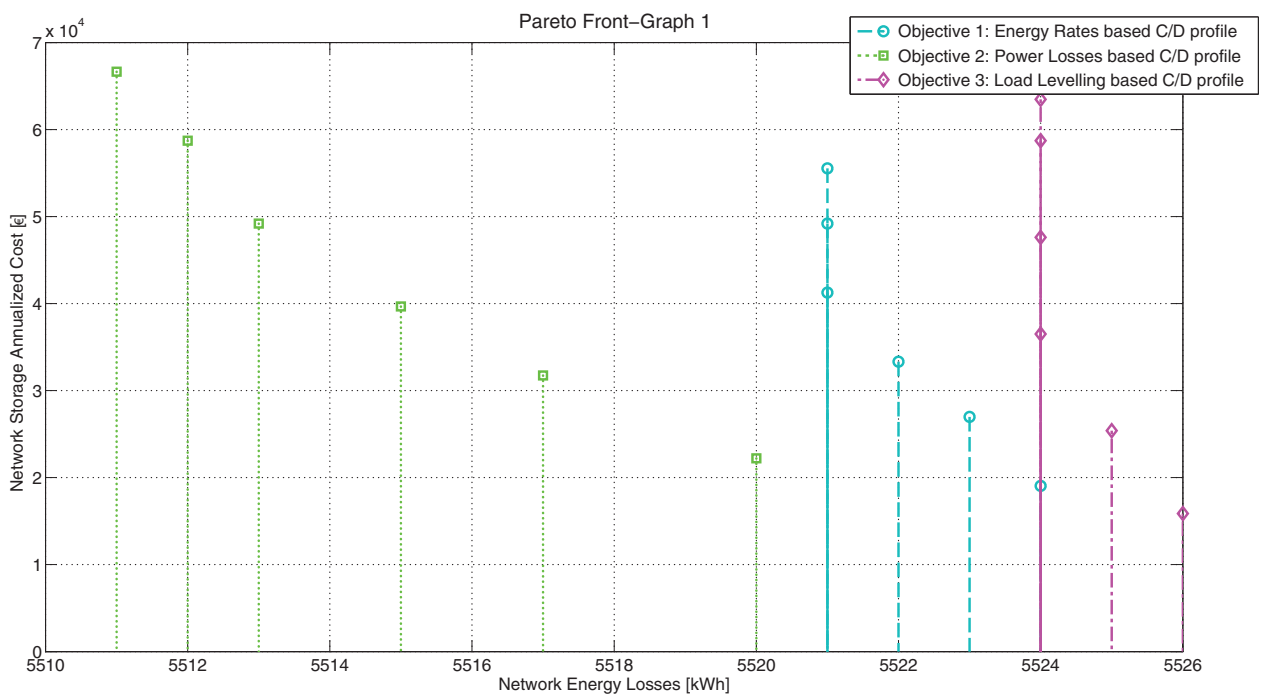

Figure 7. 2D representation results for NEL, NSAC.

Table 3. Comparison results for MSch 1 and 3 with $5524 \mathrm{kWh}$ NEL result.

\begin{tabular}{|c|c|c|c|c|c|c|c|c|c|c|c|c|c|c|}
\hline $\begin{array}{l}\text { Bus } \\
\text { N. }{ }^{\circ}\end{array}$ & $\begin{array}{c}\text { MSch } \\
1\end{array}$ & $\begin{array}{c}\text { MSch } \\
3\end{array}$ & $\begin{array}{l}\text { Bus } \\
\text { N. }{ }^{\circ}\end{array}$ & $\begin{array}{c}\text { MSch } \\
1\end{array}$ & $\begin{array}{c}\text { MSch } \\
3\end{array}$ & $\begin{array}{l}\text { Bus } \\
\text { N. }{ }^{\circ}\end{array}$ & $\begin{array}{c}\text { MSch } \\
1\end{array}$ & $\begin{array}{c}\text { MSch } \\
3\end{array}$ & $\begin{array}{l}\text { Bus } \\
\text { N. }\end{array}$ & $\begin{array}{c}\text { MSch } \\
1\end{array}$ & $\begin{array}{c}\text { MSch } \\
3\end{array}$ & $\begin{array}{l}\text { Bus } \\
\text { N. }\end{array}$ & $\begin{array}{c}\text { MSch } \\
1\end{array}$ & $\begin{array}{c}\text { MSch } \\
3\end{array}$ \\
\hline 6 & 0 & 0 & 17 & 0 & 1 & 33 & 0 & 0 & 48 & 0 & 0 & 62 & 1 & 1 \\
\hline 7 & 0 & 0 & 18 & 1 & 1 & 34 & 0 & 0 & 49 & 0 & 0 & 64 & 1 & 0 \\
\hline 8 & 0 & 1 & 20 & 1 & 1 & 35 & 0 & 0 & 50 & 0 & 0 & 65 & 0 & 1 \\
\hline 9 & 1 & 0 & 21 & 0 & 1 & 37 & 0 & 0 & 51 & 0 & 1 & 66 & 0 & 0 \\
\hline 10 & 0 & 1 & 22 & 1 & 0 & 39 & 0 & 1 & 52 & 0 & 0 & 67 & 0 & 0 \\
\hline 11 & 0 & 1 & 24 & 0 & 1 & 40 & 0 & 0 & 53 & 0 & 0 & 68 & 1 & 0 \\
\hline 12 & 1 & 0 & 26 & 1 & 1 & 41 & 0 & 1 & 54 & 0 & 0 & 69 & 0 & 1 \\
\hline 13 & 0 & 1 & 27 & 0 & 0 & 43 & 0 & 0 & 55 & 0 & 1 & & & \\
\hline 14 & 0 & 1 & 28 & 0 & 0 & 45 & 1 & 1 & 59 & 1 & 1 & & & \\
\hline 16 & 0 & 1 & 29 & 0 & 0 & 46 & 0 & 0 & 61 & 1 & 1 & & & \\
\hline
\end{tabular}

Regarding VD, the existence of the proposed storage reduced deviations in approximately 5\%, corresponding to a difference of $0.005 \mathrm{pu}$ in at least one bus voltage.

In Figure 7, an analysis of the two-dimensional plan shows that for similar NSAC, different NEL could be obtained, depending on the management scheme. As expected, MSch 2, representing the goal of reducing energy losses, presented the best results for this objective.

Considering the results obtained for MSch 1 and 3, the authors found that for solutions with similar NEL results of $5524.0 \mathrm{kWh}$, only 7 out of 48 buses were identical, as presented and marked in bold in Table 3. These results show that predefining the admissible buses for DEESS installation and capacity optimisation, as performed by some authors (Ippolito et al. 2014; Fossati et al. 2015), may present some limitations, as different buses may present different advantages for different energy services.

The choice of the solution of interest among the set of non-dominated solutions of Pareto front will require an analysis by the DM. As an example, a line can be drawn as shown in Figure 7, with a constant NSAC, representing the maximum admissible investment level to be considered. The intersection of that line with a bi-dimensional Pareto front represents a possible attractive solution from the point of view of the DM. The corresponding location for the storage units can then be represented on the network topology scheme, as presented in Figure 8. 


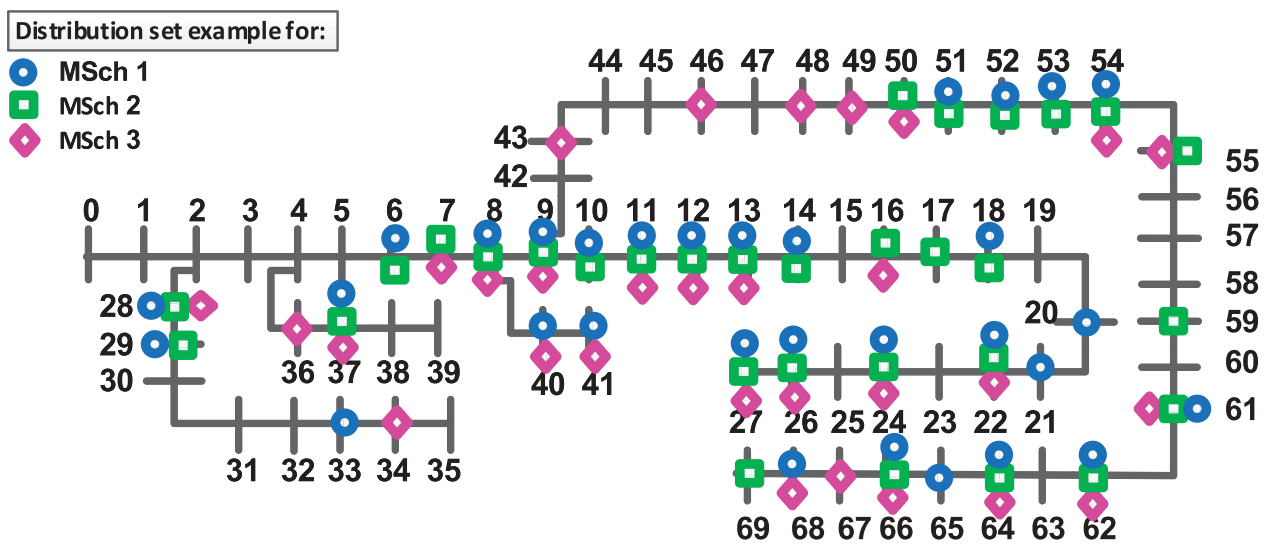

Figure 8. Location set for DEESS installation considering the three management schemes.

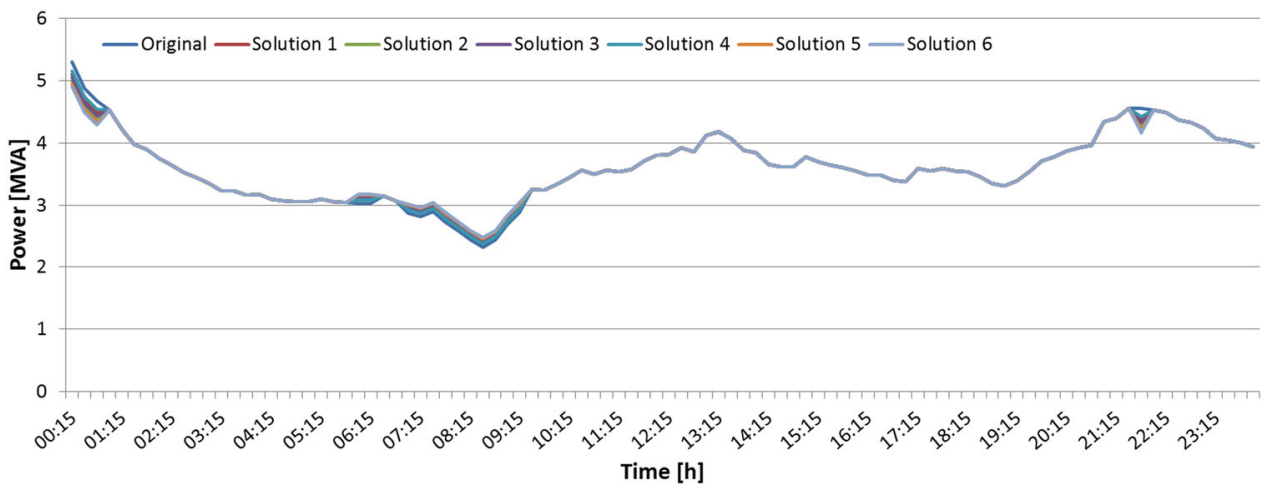

Figure 9. MSch 2 non-dominated solutions impact on the SE LD.

For the specific DM preferences used in the example, repeated DEESS locations were obtained for different management schemes, namely in nodes $8,9,11,12,13,22,24,26,27,28,37,54$, $61,62,64$ and 66. This behaviour pattern reveals the most critical nodes in the network in which storage obtains the best results according to the stated preferences.

Considering the economic perspective, the obtained results in MSch 1 are not economically appealing since the highest results only achieve around $7 € /$ day, roughly $2555 € /$ year, for a total estimated annualised cost of $55541 €$.

Even with a surplus feed-in tariff, the efficiency of storage devices and the limited use of power resulting from a limited number of C/D cycles is the cause of a not sufficiently attractive income, showing that significant efficiency improvements are highly desirable if the operational advantages of DEESS are to be matched to a real business opportunity.

Considering the total network capacity impact, the case-study results show that DEESS may reduce roughly by an average of $393 \mathrm{kVA}(8.4 \%)$ when discharging, only increasing LD by $3.2 \%$ when charging the batteries. Figure 9 shows the influence of DEESS in the daily diagram for all the non-dominated solutions of MSch2.

Even without economic attractiveness for simply buying and selling energy, results show how important DEESS may prove to be for a network, providing power services which can be paid for. An example may be the possibility of replacing at least part of the existing conventional generators which are being used simply as backup generators. 
Table 4. Sensitivity analysis applied to objective function NERB.

\begin{tabular}{|c|c|c|c|c|c|c|c|c|c|c|c|}
\hline \multirow[b]{2}{*}{$\mathrm{N} .^{\circ}$} & \multicolumn{2}{|c|}{ Feed-in tariff } & \multicolumn{2}{|c|}{ MSch 1-NERB } & \multirow[b]{2}{*}{ Annual (€) } & \multicolumn{3}{|c|}{ MSch 2-NERB } & \multicolumn{3}{|c|}{ MSch 3-NERB } \\
\hline & $(€)$ & Variation $(\%)$ & Daily (€) & Variation (\%) & & Daily (€) & Variation (\%) & Annual (€) & Daily (€) & Variation (\%) & Annual $(€)$ \\
\hline 1 & 28.14 & 0 & 5.3 & 0 & 1939.8 & 6.4 & 0 & 2342.4 & 5.5 & 0 & 2013.0 \\
\hline 2 & 38.14 & 36 & 7.8 & 47 & 2854.8 & 10.0 & 56 & 3660.0 & 9.0 & 64 & 3294.0 \\
\hline 3 & 48.14 & 71 & 10.3 & 94 & 3769.8 & 13.5 & 111 & 4941.0 & 12.6 & 129 & 4611.6 \\
\hline 4 & 58.14 & 107 & 12.8 & 142 & 4684.8 & 17.1 & 167 & 6258.6 & 16.1 & 193 & 5892.6 \\
\hline 5 & 68.14 & 142 & 15.3 & 189 & 5599.8 & 20.6 & 222 & 7539.6 & 19.7 & 258 & 7210.2 \\
\hline 6 & 78.14 & 178 & 17.8 & 236 & 6514.8 & 24.2 & 278 & 8857.2 & 23.2 & 322 & 8491.2 \\
\hline 7 & 88.14 & 213 & 20.3 & 283 & 7429.8 & 27.7 & 333 & 10138.2 & 26.8 & 387 & 9808.8 \\
\hline 8 & 501.1 & 1681 & 123.4 & 2228 & 45164.4 & 174.4 & 2625 & 63830.4 & 173.5 & 3055 & 63501.0 \\
\hline 9 & 522.9 & 1758 & 128.8 & 2330 & 47140.8 & 182.2 & 2747 & 66685.2 & 181.2 & 3195 & 66319.2 \\
\hline 10 & 614.8 & 2085 & 151.8 & 2764 & 55558.8 & 214.8 & 3256 & 78616.8 & 213.8 & 3787 & 78250.8 \\
\hline
\end{tabular}

1
0
0
0
0
0
0
0
0
0
0
0
0
0
0
0
0




\subsection{Sensitivity analysis}

Using the optimisation process results as reference, several feed-in tariffs were simulated to verify the associated NERB and also to make a preliminary assessment of the values required for obtaining a positive net benefit of deploying DEESS.

From the non-dominated solutions associated to each MSch, the authors chose the solutions with the highest NERB, one with 26 batteries, regarding MSch 1 and others with 37 batteries under MSch 2 and 3.

A sensitivity analysis was performed, testing variations on the surplus feed-in tariff. Results are presented in Table 4, showing that the relative variation of the tariff is likely to produce an even higher impact on the benefits. As an example, for a $36 \%$ variation of the surplus feed-in tariff, the NERB increased by $47 \%, 56 \%$ and $64 \%$, depending on the MSch being 1, 2 or 3, respectively. However, DEESS only presents a net positive economic result if the surplus feed-in tariff increases to approximately 614.8€/MWh, 522.9€/MWh and 501.1€ for MSch 1, 2 and 3, respectively. Such values are approximately 17-21 times the surplus feed-in tariff used in the year 2008 .

Even considering a hypothetical efficiency of $100 \%$, DEESS would need a surplus feed-in tariff between 14 and 17 times the one currently used.

These results show that DEESS can only become attractive if the economic benefit results from more than just energy purchasing and selling. Future viability will also have to include power demand services besides energy service, taking profit of its fast response capability to network requests of power demand.

\section{Conclusions}

This paper presents a methodology to provide the DM with information on the impacts, both economic and technical, of possible management schemes of ESS, to allow the choice of the best location for distributed storage devices.

The obtained results show that the best DEESS location depends on the energy service to be provided, showing that the pre-definition of locations may disregard options that would perform better towards a defined goal.

Except for PL and VD, the chosen objectives are not correlated, making the use of a multiobjective GA a suitable choice for this problem. The consequence is that, instead of being presented with an 'optimal solution', the DM will have to choose the preferred solution from the highest quality set of non-dominated solutions presented by the search tool, assuming tradeoffs between the objectives.

The presented work also discussed the possibility of providing a regulatory framework that may stimulate the existence of market players intending to invest on energy storage. One possible solution may be the use of a feed-in tariff scheme.

Results show that a higher technological efficiency of DEESS devices is very important to achieve positive economic benefits. Even with the possible future use of a suitable feed-in tariff, DEESS feasibility may depend of combining energy, power and environmental services for increasing its economic attractiveness.

\section{Disclosure statement}

No potential conflict of interest was reported by the authors.

\section{Funding}

This work has been framed under the Energy for Sustainability Initiative of the University of Coimbra and supported by the Energy and Mobility for Sustainable Regions Project CENTRO-07-0224-FEDER-002004, co-funded by the 
European Regional Development Fund (ERDF) through the «Programa Operacional Regional do Centro 2007-2013 (PORC)», in the framework of the «Sistema de Apoio a Entidades do Sistema Científico e Tecnológico Nacional», and by the «Fundação para a Ciência e Tecnologia». The work was also funded by the «Fundação para a Ciência e Tecnologia» under PEst-OE/EEI/UI0308/2014 and UID/MULTI/00308/2013.

\section{ORCID}

José António Ribeiro Gonçalves (iD) http://orcid.org/0000-0003-3389-199X

Luís Pires Neves (D) http://orcid.org/0000-0002-2600-5622

António Gomes Martins (iD http://orcid.org/0000-0002-6805-0851

\section{References}

Balcells, Josep, and Josep García. 2010. "Impact of Plug-in Electric Vehicles on the Supply Grid.” In 2010 IEEE Vehicle Power and Propulsion Conference, 1-4. IEEE. doi:10.1109/VPPC.2010.5729217.

Battistelli, C., L. Baringo, and A. J. Conejo. 2012. "Optimal Energy Management of Small Electric Energy Systems Including V2G Facilities and Renewable Energy Sources.” Electric Power Systems Research 92 (November): 5059. doi:10.1016/j.epsr.2012.06.002.

Chen, Tsai-hsiang, Ting-yen Hsieh, Nien-Che Yang, Jin-shyr Yang, and Ching-jung Liao. 2013. "Evaluation of Advantages of an Energy Storage System Using Recycled EV Batteries." International Journal of Electrical Power \& Energy Systems 45 (1): 264-270. doi:10.1016/j.ijepes.2012.08.037.

Deb, K., A. Pratap, S. Agarwal, and T. Meyarivan. 2002. "A Fast and Elitist Multiobjective Genetic Algorithm: NSGAII." IEEE Transactions on Evolutionary Computation 6 (2): 182-197.

Divya, K. C., and J. Østergaard. 2009. "Battery Energy Storage Technology for Power Systems - An Overview." Electric Power Systems Research 79 (4): 511-520.

Dufo-López, R., and J. L. Bernal-Agustín. 2015. "Techno-economic Analysis of Grid-Connected Battery Storage." Energy Conversion and Management 91: 394-404.

EDP Distribuiçao. 2004. POSTOS DE TRANSFORMAÇÃO MT / BT DE DISTRIBUIÇÃO. http://www.edpdistribuicao. pt/pt/profissionais/Lists/EDPDocumentosNormativos/Attachments/340/DMA-C13-910N.pdf.

EPRI. 2010. Electric Energy Storage Technology Options: A White Paper Primer on Applications, Costs, and Benefits. Palo Alto, CA: EPRI.

ERSE. 2013. Informação Sobre Produção Em Regime Especial (PRE). Portugal Continental. Dados Actualizados a Maio de 2013. Lisboa, Portugal: ERSE-Entidade Reguladora dos Serviços Energéticos.

Fossati, J. P., Ainhoa Galarza, Ander Martín-Villate, and Luis Fontán. 2015. "A Method for Optimal Sizing Energy Storage Systems for Microgrids.” Renewable Energy 77: 539-549.

Ippolito, M. G., M. L. Di Silvestre, E. Riva Sanseverino, G. Zizzo, and G. Graditi. 2014. "Multi-objective Optimized Management of Electrical Energy Storage Systems in an Islanded Network with Renewable Energy Sources Under Different Design Scenarios.” Energy 64: 648-662.

Kempton, W., and J. Tomić. 2005. "Vehicle-to-grid Power Fundamentals: Calculating Capacity and net Revenue." Journal of Power Sources 144 (1): 268-279.

Kristoffersen, T. K., K. Capion, and P. Meibom. 2011. "Optimal Charging of Electric Drive Vehicles in A Market Environment." Applied Energy 88 (5): 1940-1948.

Lassila, Jukka, Juha Haakana, Ville Tikka, and Jarmo Partanen. 2012. "Methodology to Analyze the Economic Effects of Electric Cars as Energy Storages.” IEEE Transactions on Smart Grid 3 (1): 506-516. doi:10.1109/TSG.2011. 2168548

Lopes, João A. Peças, Filipe Joel Soares, and Pedro M. Rocha Almeida. 2011. "Integration of Electric Vehicles in the Electric Power System.” Proceedings of the IEEE 99 (1): 168-183. doi:10.1109/JPROC.2010.2066250.

Marra, Francesco, Guang Ya Yang, Esben Larsen, Claus Nygaard Rasmussen, and Shi You 2012. "Demand Profile Study of Battery Electric Vehicle under Different Charging Options." In 2012 IEEE Power and Energy Society General Meeting, 22-26 July 2012, 1-7. San Diego, CA: IEEE. doi:10.1109/PESGM.2012.6345063.

Miranda, V., D. Srinivasan, and L. Proença. 1998. "Evolutionary Computation in Power Systems." International Journal of Electrical Power \& Energy Systems 20 (2): 89-98.

NEC. 2013. Grid Storage Solution (GSS). 8 p. Westborough, MA: NEC Energy Solutions, Inc. http://www.neces.com/assets/ NEC_Grid_Brochure_MD100120-02-5.pdf.

OMIP. 2013. http://www.omip.pt/Downloads/tabid/104/language/pt-PT/Default.aspx.

Ribeiro, P. F., B. K. Johnson, M. L. Crow, A. Arsoy, and Y. Liu. 2001. "Energy Storage Systems for Advanced Power Applications." Proceedings of the IEEE 89 (12): 1744-1756.

Sahoo, N. C., and K. Prasad. 2006. "A Fuzzy Genetic Approach for Network Reconfiguration to Enhance Voltage Stability in Radial Distribution Systems." Energy Conversion and Management 47 (18-19): 3288-3306.

Schoenung, Susan. 2011. Energy Storage Systems Cost Update A Study for the DOE Energy Storage Systems Program (Report SAND2011-2730). Albuquerque: Sandia National Laboratories. http://prod.sandia.gov/techlib/access-control. cgi/2011/112730.pdf 
Sovacool, B. K., and R. F. Hirsh. 2009. "Beyond Batteries: An Examination of the Benefits and Barriers to Plug-in Hybrid Electric Vehicles (PHEVs) and A Vehicle-to-Grid (V2G) Transition." Energy Policy 37 (3): 1095-1103.

Systems, A. 2013. Nanophosphate Basics: An Overview of the Structure, Properties and Benefits of A123 Systems 'Proprietary Lithium Ion Battery Technology.

Thunder Sky. 2007. Instruction Manual for LFP/LCP/LMP Lithium Power Battery. Shenzhen: Thunder Sky Company. http://www.thunderstruck-ev.com/Manuals/Thundersky Product Manual.pdf.

Vasconcelos, J., et al. 2012. Electricity Storage: How to Facilitate its Deployment and Operation in the EU Final Report. Firenze/Taipei, Taiwan: European University Institute/European Union Centre in Taiwan.

Vitorino, R. M., H. M. Jorge, and L. P. Neves. 2013a. "Loss and Reliability Optimization for Power Distribution System Operation." Electric Power Systems Research 96: 177-184.

Vitorino, R. M., H. M. Jorge, and L. P. Neves. 2013b. "Multi-objective Optimization Using NSGA-II for Power Distribution System Reconfiguration.” International Transactions on Electrical Energy Systems, p.n/a-n/a. Accessed January 18, 2014. http://doi.wiley.com/10.1002/etep.1819. 